\title{
Corrigendum to "Overview of the field measurement campaign in Hyytiälä, August 2001 in the frame of the EU project OSOA" published in Atmos. Chem. Phys., 4, 657-678, 2004
}

M. Boy et al.

Dept. of Physics, University of Helsinki, P.O. Box 64, FIN-00014, Finland (UHEL)

The authors regret that in the above article the following error occurred:

Page 669, Figs. 13b, c, d, e, and f: The units of concentration for the photooxidation products should have appeared as $\mathrm{ng} / \mathrm{m}^{3}$ (nanograms per cubic meter).

Correspondence to: M. Boy

(michael.boy@helsinki.fi) 